Jpn. J. Phys. Fitness Sports Med., 60 (3) : 311 318 (2011)

\title{
Hydration habits in elite futsal players during official games
}

\author{
García-Jiménez, J.V.1), Yuste, J.L. ${ }^{1)}$, García-Pellicer, J.J.' ${ }^{1)}$ \\ Pérez-Jorge, J.A.2) and López-Román, F.J.3)
}

(Received December 4, 2010; Accepted April 12, 2011)

\begin{abstract}
Futsal is a variant of soccer that is played on a smaller playing surface and mainly played indoors. It is played between two teams of five players, and unlimited substitutions per team are permitted. The purpose of this study has been to determine the body water balance and level of dehydration in field futsal players from an elite team during competition. Eight male elite futsal players (mean \pm SD: age: $23.5 \pm 4.5 \mathrm{yrs}$; weight $76.5 \pm 6.8 \mathrm{~kg}$; height $1.80 \pm 0.12 \mathrm{mt}$ ) participated in the present study during six official games (Ta; $22-26^{\circ} \mathrm{C}, \mathrm{RH} ; 32-42.33 \%$ ) from the first division league in Spain. Sweat loss was calculated by the body weight looses in pre- and post-game after collection of fluid intake and urine loss. Mean fluid intake (FI) was $1.6 \pm 0.7 \mathrm{~L}$. consuming $71.0 \pm 33.3 \%$ of total fluid loss. The body weight loss was $0.7 \pm 0.8 \mathrm{Kg}$, equivalent to a level of dehydration $(\mathrm{DH})$ of $0.9 \pm 1.1 \%$, which is not related to a reduction in performance. There are no significant differences in FI and DH results obtained between the games $(p>0.05)$. We conclude that, in the players from the analyzed team, hydration status can be seen to maintain itself through regular substitutions and the correct level of fluid intake. However, data allow for an individualisation of player's hydration strategies.
\end{abstract}

(Jpn. J. Phys. Fitness Sports Med., 60 (3) : 311 318 (2011))

Key words : Fluid intake, dehydration, futsal, competition.

\section{I . Introduction}

Futsal is a variant of soccer that is played on a smaller playing surface (40x20 mt.) and mainly played indoors. Futsal is played between two teams of five players, one of whom is the goalkeeper, and four field players. Unlimited substitutions per team are permitted. It is an intermittent high intensity sport, where the main energy pathway is the anaerobic metabolism.

Dehydration is known to affect thermoregulatory responses and exercise performance. The maintenance of blood volume is an important factor for providing circulatory stability, thermoregulatory and maintaining performance during exercise Kawabata et al. ${ }^{1)}$. The fact that the blood volume associates with thermoregulatory responses and contributes to inhibition of hyperthermia in exercise has been reported by previous study Convertino ${ }^{2)}$, Fortney et $a l^{3)}$, Mack et al. ${ }^{4)}$. It has been well known that hypervolemia induced by thermal dehydration and progressive pooling of blood in cutaneous blood vessel in response to heat stress reduces the central circulating blood volume. Under these conditions cutaneous vasoconstriction leads to excessive heat storage in hot environment Kawabata et al. ${ }^{1)}$. Increases in sweat rate and skin blood flow during exercise in hot environment enhance heat dissipation and prevent hyperthermia. Hyperthermia itself has been suggested to limit aerobic performance Nielsen et al. ${ }^{5)}$

To avoid a reduction in performance during games, players must ingest enough fluid to match their sweat loss Burke ${ }^{6)}$, Maughan and Gleeson ${ }^{7)}$, Murray $^{8)}$ Dehydration occurs when fluid loss by sweating is higher than fluid intake Jeukendrup ${ }^{9)}$

\footnotetext{
1) Department of Physical Education, Faculty of Education, University of Murcia, Spain.

2) Department of Physical Education and Sport, Faculty of Education. University of Córdoba. Spain.

3) Department of Exercise Physiology. San Antonio Catholic University. Mucia. Spain.
} 
and it is common when athletes do not ingest enough fluid to match their sweat lost Maughan and Gleeson ${ }^{7)}$, Jeukendrup and Gleeson ${ }^{10)}$, Palacios et al. ${ }^{11)}$, Wilmore and Costill ${ }^{12)}$.

Because dehydration is a limiting factor for mental and physical performance during sport and physical activity Casa et al. ${ }^{13)}$, Cheuvront et al. ${ }^{14)}$, Coyle ${ }^{15)}$, Sawka et al. ${ }^{16)}$, Tomporowsky et al. ${ }^{17)}$, Murray ${ }^{18)}$, Maughan et al. ${ }^{19)}$, Murray ${ }^{20)}$, it is extremely important to understand athlete's hydration habits, and to intervene when necessary.

A simple way to determine the level of dehydration achieved in futsal players is to weigh the athlete before and after performing the exercise, as the average loss of water through respiration in intermittent activity lasting less than 3 hours, and normal weather conditions, is barely significant compared to the loss through sweating Maughan et al. ${ }^{19)}$. The use of pre- to post-exercise change in body mass provides a estimation of total fluid loss due to sweating Burke ${ }^{6)}$, Maughan and Gleeson ${ }^{7)}$, Maughan et $\mathrm{al}^{19)}$, Murray ${ }^{20)}$. Therefore, measurement of body weight changes is a simple, noninvasive and valid approach to estimate hydration changes in team sports, by calculating the difference in body weight pre- and post-exercise Barbero et al. ${ }^{21)}$, Harvey et al. ${ }^{22)}$, Wickwire et al. $^{23)}$.

A body water deficit greater than $2 \%$ of body weight marks the level of dehydration that can adversely affect physical performance Jeukendrup ${ }^{9)}$, Palacios et al. ${ }^{11)}$,Wilmore and Costill ${ }^{12)}$, Casa et al. ${ }^{13)}$, Sawka et al. ${ }^{16)}$, Manore et al. ${ }^{24)}$, Montain ${ }^{25)}$ and to reduce the athlete's cognitive function as perceptual discrimination or reaction time Cheuvront et al. ${ }^{14)}$, Sawka et al. ${ }^{16)}$. This data is particularly relevant to our study because the performance of a futsal player, independently of playing position, will depend on both their physical condition and cognitive abilities to make right decisions in the shortest time.

In team sports, in addition to individual differences in sweat rates of players like body weight, genetic predisposition, or heat acclimatization state
Maughan et al. ${ }^{19)}$, Broad et al. ${ }^{28)}$, the results of the players depending on their specific position, can vary considerably in intensity and duration of exercise during a game Jeukendrup ${ }^{9}$, changing dehydration levels Maughan and Gleeson ${ }^{7)}$, Jeukendrup ${ }^{9)}$. For this reason, our work is focused exclusively on field players (not goalkeepers).

Our investigation has studied elite futsal players during official games. The team analyzed is considered one of the best in the world, and the analysis of its players provides valuable information about futsal hydration habits during real competition. In similar articles published by studying firstlevel players, researchers are required to simulate competitive situations in training sessions Godek et al. $^{27)}$, Broad et al. ${ }^{28)}$, Cox et al. ${ }^{29)}$, Martarelli et $\mathrm{al}^{30)}$, Maughan et al. ${ }^{31)}$, Shirrefs et al. ${ }^{32)}$.

The aim of this study was to calculate sweat loss, voluntary fluid replacement and levels of dehydration in field futsal players from an elite team during six official games, through the measurement of body weight changes, urine loss and total fluid intake.

\section{Material and Methods}

\section{A. Participants}

8 male field futsal players (not goalkeepers), from the first team squad of a professional club, were informed and gave their written consent to participate in this study, after the details had been explained to them. The study was approved by the Institutional Review Board at the University of Murcia (Spain). All players are professionals, with years of experience. Seven of whom are international with their national teams. Physical characteristics of the players were: age $23.5 \pm 4.5$ years; height $1.80 \pm 0.12 \mathrm{mt}$; body weight $76.5 \pm 6.8 \mathrm{~kg}$.

Due to the difficulty to study other teams in the same level to get a representative sample, selection was done using non-probability sampling, having performed the selection for convenience. Therefore, and because the sample is not representative, we can not extrapolate the results of this research to 
Table 1. Timing and climate conditions of games*

\begin{tabular}{ccccc}
\hline $\mathbf{G W}^{\star *}$ & Date & Time & Temperature $\left(^{\circ} \mathrm{C}\right)$ & Relative Humidity (\%) \\
\hline 19 & $4 / 02 / 2006$ & $18^{\prime} 30 \mathrm{~h}$. & 22 & 42 \\
21 & $18 / 02 / 2006$ & $13^{\prime} 45 \mathrm{~h}$. & 24 & 39.33 \\
23 & $4 / 03 / 2006$ & $18^{\prime} 30 \mathrm{~h}$. & 22 & 40 \\
25 & $18 / 03 / 2006$ & $18^{\prime} 30 \mathrm{~h}$. & 22 & 40 \\
27 & $1 / 04 / 2006$ & $13^{\prime} 45 \mathrm{~h}$. & 26 & 32 \\
29 & $15 / 04 / 2006$ & $18^{\prime} 30 \mathrm{~h}$. & 24.8 & 42.33 \\
\hline
\end{tabular}

*All games were played in Murcia, Spain ** GW: Gameweek

other futsal teams.

Data were collected during six official games from the First Division League in Spain, corresponding to gameweeks 19, 21, 23, 25, 27 and 29 (Table 1).

\section{B. Procedures}

A meteorological station OREGON SCIENTIFIC WMR-80 (Oregon ${ }^{\circledR}$, Hunghom, China), was used to record temperature and relative humidity, using the mean value recorded since the start of warm-up to the final whistle.

To measure body weight we followed the protocol developed by the International Society for the Advancement of Kinanthropometry (Norton et $\mathrm{al}^{33)}$. We used a scale TANITA BC-350 (Tanita ${ }^{\circledR}$, Illinois, USA) with 97\% reliability, accuracy 0.1 $\mathrm{kg}$. and a measurement range from 0 to $150 \mathrm{~kg}$. Players were weighed without clothing before the warm-up and after the game. Players were asked to micturate and defecate if necessary prior to the pre-warm-up measurement. Before weighing the players at the end of the game, perspiration was wiped of the player's legs, body and face with a towel, as indicated by Barbero et al. ${ }^{21)}$ in their study.

The percentage of body weight loss was calculated using the formula Martins et al. ${ }^{34)}$ :

\% Body weight lost: [(Pre-game weight - Postgame weight)/Pre-match weight] x 100
Each player was provided with the water (Aquadeus) and the sports drink (Gatorade) of 500 $\mathrm{ml}$, respectively. The players had been consuming these two drinks throughout the season.

The volume of fluid introduced into each bottle was previously measured in a graduated test-tube with capacity of $1000 \mathrm{ml}$. and 1000:10 calibrated. The players were instructed to drink only from their own numbered bottles, just as they were told that in case they need more liquid they should advise the researcher so that he could fill the bottles. Fluid intake was ad libitum. Once the game concluded, by subtracting the amount of liquid remaining in the player's bottle from the amount given to them, the total value for liquid consumed is yielded.

The volume of urine excreted by the players was measured since the warming-up to the end the game. After the first weighing of the players, and there after, the player had to urinate in a sterile and personal container, 1000:10 calibrated and prepared for urine collection.

Total sweat loss was calculated using the formula Murray ${ }^{8)}$ :

Sweat loss $=($ Pre-game weight + Fluid intake Post-game weight - Urine excreted)

Each player's game time was obtained by adding up the minutes played and warm-up time (standardized to 30 minutes). During the game, the exact time when the player started and stopped 
playing was recorded. Finally, the time played was calculated by adding each player's action.

\section{Statistical analysis}

Average values (game time, weight loss, fluid intake and excreted urine) are reported as means \pm SD. One-way analysis of variance (ANOVA) followed by Bonferroni post hoc comparison was used to determine significant differences between the results obtained in different games. For all procedures statistical significance was $\mathrm{p} \leq 0.05$. The SPSS 15.0 statistics package was used for the analysis.

\section{Results}

The mean results for all variables from the six games are presented in table 2 . There were no significant differences in relation to game played, according to Bonferroni post hoc test $(\mathrm{p}>0.9$ for all variables).

Mean fluid intake by players was $1.6 \pm 0.7 \mathrm{~L}$. The calculated average of sweat loss by players was 2.2 $\pm 0.8 \mathrm{~L}$. On average $71.0 \pm 33.3 \%$ of the body fluid replacement during games. The level of dehydration was $0.9 \pm 1.1 \%$ of the pre-match body weight, ranging from 0.8 to $1.1 \%$ dehydration.

\section{N. Discussion}

In this study we have obtained the level of dehydration in elite field futsal players during six official games. The results show that fluid replacement was enough to offset losses caused by sweat.

Futsal played at highest level demands an excellent physical condition in players due to the physiological demands involved in competition (approximately 90\% of maximum heart rate) Barbero et al. ${ }^{35)}$, Castagna et al. ${ }^{36)}$. A high performance player needs an excellent ability to perform high-intensity intermittent exercise, and a rapid recovery during low-intensity activities. In this sense an adequate fluid replacement strategy is essential to avoid reduced performance Jeukendrup ${ }^{10)}$, Palacios et al. ${ }^{11)}$, Sawka et al. ${ }^{16)}$, Barbero et $\mathrm{al}^{21}{ }^{21}$, Al-Taser and Hasan ${ }^{37)}$.

In this study, as a result of fluid loss through sweating players incurred an average body mass deficit of $0.9 \pm 1.1 \%$, so they were aware of the impact that dehydration has on performance Wilmore and Costill ${ }^{12)}$, Cheuvront et al. ${ }^{14)}$, Maughan et al. $^{19)}$, Murray ${ }^{20)}, \mathrm{ACSM}^{26)}$. Due to the characteristics of futsal, it is recommended not to exceed $2 \%$ body weight loss, as dehydration is associated with

Table 2. Mean \pm SD of game time, fluid balance and dehydration in relation to game played $(n=8)$

\begin{tabular}{cccccccc}
\hline & GW 19 & GW 21 & GW 23 & GW 25 & GW 27 & GW 29 & MEAN \\
\hline Game time (min) & $50.14 \pm 4.2$ & $47.78 \pm 6.2$ & $50.0 \pm 3.3$ & $47.88 \pm 4.01$ & $47.78 \pm 5.76$ & $50.0 \pm 3.07$ & $\mathbf{4 8 . 8 6 \pm 4 . 5 6}$ \\
Body mass loss (kg) & $0.6 \pm 0.8$ & $0.6 \pm 0.9$ & $0.8 \pm 0.8$ & $0.7 \pm 0.9$ & $0.7 \pm 0.9$ & $0.8 \pm 0.8$ & $\mathbf{0 . 7 \pm 0 . 8}$ \\
Fluid intake (L) & $1.3 \pm 0.7$ & $1.8 \pm 0.9$ & $1.5 \pm 0.6$ & $1.4 \pm 0.7$ & $1.9 \pm 0.8$ & $1.5 \pm 0.6$ & $\mathbf{1 . 6 \pm 0 . 7}$ \\
Excreted urine (L) & $0.2 \pm 0.1$ & $0.2 \pm 0.2$ & $0.2 \pm 0.9$ & $0.2 \pm 0.1$ & $0.2 \pm 0.2$ & $0.2 \pm 0.9$ & $\mathbf{0 . 2 \pm 0 . 1}$ \\
Sweat loss (L) & $1.7 \pm 0.7$ & $2.3 \pm 1.0$ & $2.1 \pm 0.5$ & $2.1 \pm 0.9$ & $2.6 \pm 0.8$ & $2.3 \pm 0.5$ & $\mathbf{2 . 2 \pm 0 . 8}$ \\
$\begin{array}{c}\text { Percentage of sweat } \\
\text { lost replaced (\%) }\end{array}$ & $71.4 \pm 37.6$ & $74.8 \pm 33.2$ & $64.3 \pm 31.7$ & $73.4 \pm 42.3$ & $75.3 \pm 33.6$ & $65.5 \pm 30.1$ & $\mathbf{7 1 . 0 \pm 3 3 . 3}$ \\
$\begin{array}{c}\text { Dehydration (\% Body } \\
\text { weight lost) }\end{array}$ & $0.8 \pm 1.1$ & $0.8 \pm 1.2$ & $1.1 \pm 1.1$ & $0.9 \pm 1.1$ & $0.9 \pm 1.2$ & $1.1 \pm 1.1$ & $\mathbf{0 . 9 \pm 1 . 1}$ \\
\hline
\end{tabular}




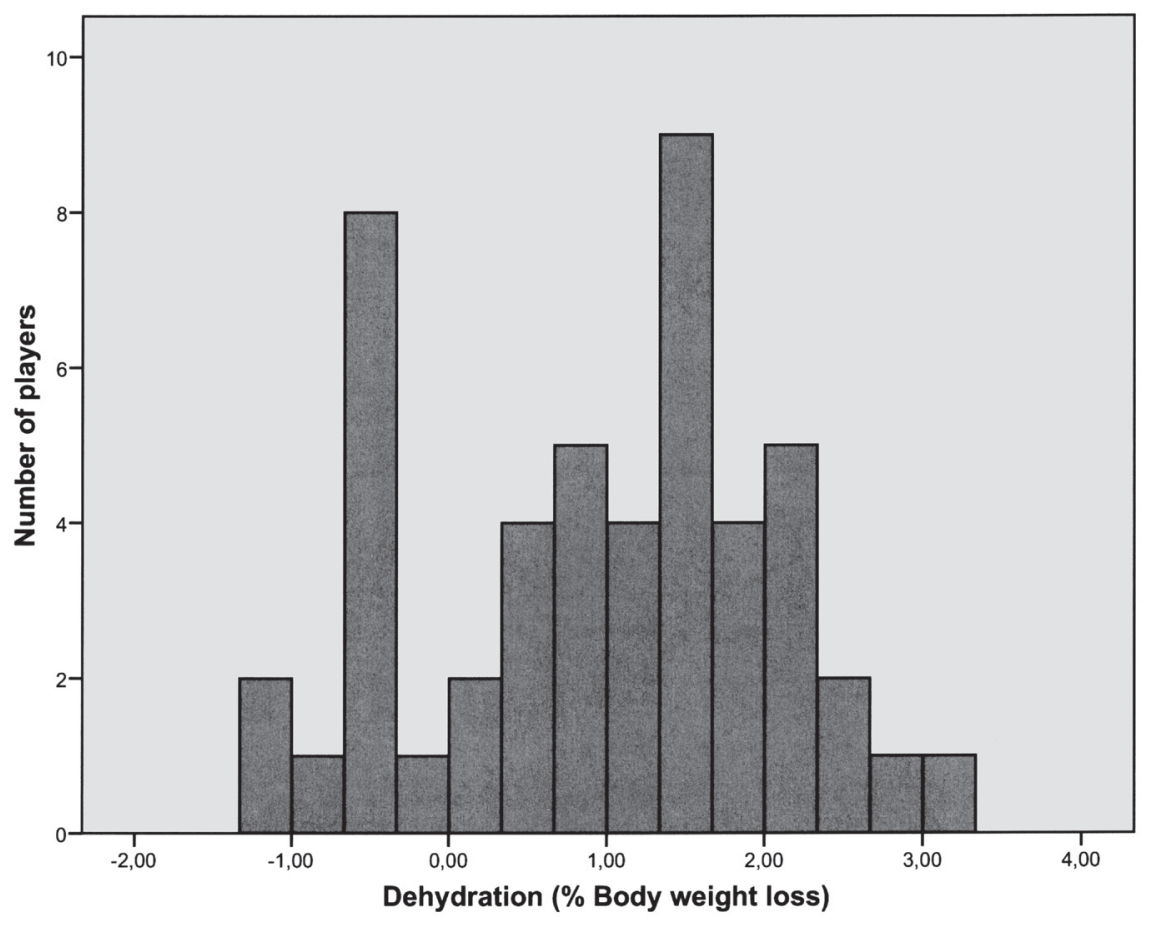

Fig.1. Distribution of dehydration at the end of the games amongst the 8 players

decreased aerobic performance and increased cardiac work ${ }^{14,19,20,26)}$, it also affecting motor sensory reactions such as reaction time and perceptual discrimination $\mathrm{ACSM}^{26)}$, Godek et al. ${ }^{27)}$.

The large individual differences in dehydration levels of players (fig.1), are in accordance with ACSM's Position Stand ${ }^{26)}$ and Shirreffs et al. ${ }^{32)}$ which tell of the difficulty in giving a universal recommendation that adequately supplies for the needs of players due to the high variability of results obtained, even among members of the same team.

However, various publications recommend to pay attention to environmental conditions, level of physical condition, intensity of effort, playing position or fluid intake to explain losses caused by dehydration Palacios et al. ${ }^{11)}$, Casa et al. $^{13)}$, Sawka et al. ${ }^{16)}$, Montain ${ }^{25)}$, Ferguson et al. ${ }^{38)}$.

The environmental conditions in which the games were played were similar (Ta; $22-26{ }^{\circ} \mathrm{C}$, RH; 32$42.33 \%$ ) because they were played in the same sports hall, which has cooling system.

To identify physical demands on players in team sports, we must study their specific characteristics and their specific position, because tactics of each position involve different levels of distance covered or intensity of effort between goalkeepers and field players Hencken and White ${ }^{39)}$. In a study of elite futsal players, field players covered more than half of the distance covered by field players (6885.06 $\mathrm{mt}$. versus $3030.71 \mathrm{mt}$.), associating this data with higher-intensity efforts Hernánez ${ }^{40)}$.

Therefore, in the first analysis, the results agreed with studies that warn that progressive dehydration during exercise is common because many athletes do not get enough fluids to replace sweat losses Burke $^{6)}$, Palacios et al. ${ }^{11)}$, Wilmore and Costill ${ }^{12)}$, Casa et al. ${ }^{13)}$, Sawka et al. ${ }^{16)}$, Ferguson et al. ${ }^{38)}$. In the sport of our study, a field futsal player has ample opportunities to hydrate, due to substitutions and breaks in play during the game. Barbero et al. $^{21)}$ calculated that every field player had 7.4 opportunities to hydrate per game.

Fluid intake in our study was ad libitum, replacing players $71.0 \pm 33.3 \%$ of the losses caused by sweat. Mean dehydration $(0.9 \pm 1.1 \%)$ shows that intake 
was sufficient to offset dehydration associated with efforts of the professional futsal games.

Average fluid intake by players in our study (1.6 $\pm 0.7 \mathrm{~L}$ ) exceeds results by Barbero et al. ${ }^{21)}$ in elite futsal players. Along these lines, another study with elite futsal players Hamouti et al. ${ }^{41)}$ obtained an average of $0.8 \mathrm{~L}$ intake after a training session, less than the total fluid intake by our players.

In other team sports, Broad et al. ${ }^{28)}$ assessed fluid intake in 12 basketball players after a game, which mean result was $1.1 \mathrm{~L}$, less than that obtained in our study $(1.6 \pm 0.7 \mathrm{~L})$. Schröder et al. ${ }^{42)}$ assessed fluid intake during training and competition sessions in 55 elite basketball players, which mean result was $0.8 \pm 0.4 \mathrm{~L}$.

Compared to studies with soccer players, fluid intake in our research $(1.6 \pm 0.7 \mathrm{~L}$ was higher than that calculated by Maughan et al. ${ }^{31)}$ and Shirreffs et $\mathrm{al}^{32)}$, who obtained a average fluid intake of 0.971 $\pm 0.3 \mathrm{~L}$ and $0.9 \pm 0.3 \mathrm{~L}$ respectively after analysing soccer players during training sessions.

As a result of fluid loss through sweat players incurred a mean body mass deficit of $0.9 \pm 1.1 \%$. These values are not related to a reduction in performance Palacios et al. ${ }^{11)}$, Casa et al. ${ }^{13)}$, Cheuvront et al. ${ }^{14)}$, Manore et al. $^{24)}$. Due to the characteristics of futsal, it is recommended not to exceed $2 \%$ of body weight lost, as dehydration is associated with decreased aerobic performance and increased cardiac work Murray ${ }^{8)}$, Jeukendrup ${ }^{9)}$, Sawka et al. ${ }^{16)}$, Barbero et al. ${ }^{21)}$, Montain, ${ }^{25)}$, it also affecting motor sensory reactions such as reaction time and perceptual discrimination Casa et al. ${ }^{13)}$, Tomporowski et al. ${ }^{17)}$, Montain ${ }^{25)}$.

In relation to futsal players, Barbero et al. ${ }^{21}$ ) assessed 13 elite futsal players, where mean percentage weight loss after three official games was $1.1 \pm 0.9 \%$, higher than that obtained from our research $(0.9 \pm 1.1 \%)$.

Hamouti et al. ${ }^{41)}$, obtained $1.2 \pm 0.3 \%$ body weight lost in elite futsal players after a training session. The mean weight loss rate is higher than that obtained by the players in our study $(0.9 \pm 1.1 \%)$.
The study conducted by Martins et al. ${ }^{34)}$ in futsal players shows values of $0.43 \pm 0.41 \%$ weight lost after assessing 6 players (15-18 y) in training session. These results are lower than those obtained by the players in our study $(0.9 \pm 1.1 \%)$

In other team sports, in an investigation of percentage of weight lost in elite basketball players, Broad et al. $^{28)}$ finds mean results were $1 \%$ loss in body weight, similar to those obtained in our study $(0.9 \pm 1.1 \%)$. Similar to this, Maughan et al. ${ }^{31}$, found a mean $1.59 \pm 0.61 \%$ weight loss in soccer field players during training. Also during a training session with soccer players, Shirreffs et al. ${ }^{32)}$ results were $1.62 \%$. In both publications, percentage weight loss was higher than in our study $(0.9 \pm 1.1 \%)$.

\section{Conclusions}

On average, fluid intake in these elite futsal players during official games was enough to offset losses caused by sweat. The mean values, however, hide the large inter-individual differences in fluid balance of the players. Results allow this elite futsal club to individualise player's hydration strategies, even so hydration status in field players can be well maintained with regular substitutions and correct fluid intake.

\section{Acknowledgements}

We thank players, coaching and managers from Elpozo Murcia Turística Fútbol Sala for their participation and collaboration in this study.

\section{References}

1) Kawabata T, Suzuki T, and Miyagawa T. Effect of blood volume on plasma volume shift during exercise. J Therm Bio, 29: 775-778, 2004.

2) Convertino VA. Heart rate and sweat rate responses associated with exercise-induced hypervolemia. Med Sci Sports Exer, 15: 77-82, 1983.

3) Fortney SM, Vroman NM, Beckett WS, Permutt S, and Lafrance ND. Effect of exercise hemoconcentration and hyperosmolarity on exercise responses. J Appl Physiol, 65: 519-524, 1988.

4) Mack GW, Nose $H$, Takamata $A$, Okuno $T$, and Morimoto T. Influence of exercise intensity and plasma volume on active cutaneous vasodilation in 
humans. Med Sci Sports Exer 26: 209-216, 1994.

5) Nielsen B, Hales JRS, Strange S, Christensen NJ, Warberg J, and Saltin B. Human circulatory and thermoregulatory adaptions with heat acclimation and exercise in hot, dry environment. J Physiol, 460: 467-485, 1993.

6) Burke LM. Fluid balance during team sports. J Sport Sci, 15(3): 287-295, 1997.

7) Maughan RJ, and Gleeson M. The Biochemical Bases of Sports Performance. Oxford: Oxford University Press, 2004.

8) Murray R. Dehydration, hyperthermia, and athletes: science and practice. J Ath Training, 31(3): 248-252, 1996.

9) Jeukendrup AE. Carbohydrate feeding during exercise. Eur J Sport Sci, 8(2): 77-86, 2008.

10) Jeukendrup AE, and Gleeson M. Sport Nutrition: An Introduction to Energy Production and Performance. Champaign, IL: Human Kinetics, 2010, pp. 202-213.

11) Palacios N, Franco L, Mamonelles P, Manuz B, and Villegas JA. Consenso sobre bebidas para el deportista. Composición y pautas de reposición de líquidos. Arch Med Deporte, 126(25): 245-258, 2008.

12) Wilmore JH, and Costill DL. Physiology of Sport and Exercise. Champaign, IL: Human Kinetics, 2007, pp. 460-462.

13) Casa DJ, Clarkson PM, and Roberts WO. American College of Sports Medicine roundtable on hydration and physical activity: consensus statements. Curr Sports Med Rep, 14: 115-127, 2005.

14) Cheuvront SN, Carter R, and Sawka MN. Fluid balance and endurance exercise performance. Curr Sports Med Rep, 2: 202-208, 2003.

15) Coyle EF. Fluid and fuel intake during exercise. J Sport Sci, 22, 39-55, 2004.

16) Sawka MN, Burke LM, Eichner ER, Maughan RJ, Montain SJ, and Stachenfeld, NS. American College of Sports Medicine position stand. Exercise and fluid replacement. Med Sci Sports Exer, 39(2): 377-390, 2007.

17) Tomporowski PD, Beasman K, Ganio MS, and Cureton K. Effects of dehydration and fluid ingestion on cognition. Int J Sports Med, 28(10): 891-896, 2007.

18) Murray R. Rehydration strategies - balancing substrate, fluid and electrolyte provision. Int J Sports Med, 19: S133-S135, 1998.

19) Maughan RJ, Shirrefs SM, and Leiper JB. Errors in the estimation of hydration status from changes in body mass. J Sport Sci, 25(7): 797-804, 2007.

20) Murray R. Hydration and physical performance. J Am Coll Nutr, 26 (5Suppl): 542S-548S, 2007.

21) Barbero JC, Castagna C, and Granda-Vera J. Deshidratación y reposición hídrica en fútbol sala. Efectos de un programa de intervención sobre la pérdida de líquidos durante competición. Motricidad. Eur J Human Mov, 17: 97-110, 2006.

22) Harvey G, Meir R, Brooks L, and Holloway K. The use of body mass changes as a practical measure of dehydration in team sports. J Sports Sci Med, 11(6): 600-603, 2008.

23) Wickwire J, Bishop PA, Green JM, Richardson MT, Lomax RG, Casaru C, Jones E, and Curtner-Smith M. Validation of a personal fluid loss monitor. Int J Sports Med, 29(2): 139-144, 2008.

24) Manore MM, Meyer NL, and Thompson J. Sport Nutrition for Health and Performance. Champaign, IL: Human Kinetics, 2008, pp. 236-241.

25) Montain SJ. Hydration recommendations for sport. Curr Sports Med Rep, 7(4): 187-192, 2008.

26) American College of Sports Medicine. ACSM Position Stand on Exercise and Fluid Replacement. Med Sci Sports Exer, 28(1): 1-7, 1996.

27) Godek SF, Bartolozzi AR, Peduzzi C, Heinerichs S, Garvin E, Sugarman E, and Burkhloeder R. Fluid consumption and sweating in national football league and collegiate football players with different access to fluids during practice. J Athl Train, 45(2): 128135, 2010.

28) Broad EM, Burke LM, Cox GR, Heeley P, and Riley M. Body weight changes and voluntary fluid intakes during training and competition sessions in team sports. Int J Sport Nutr Exerc Metanol, 6: 307-320, 1996.

29) Cox GR, Broad EM, Riley MD, and Burke LM. Body mass changes and voluntary fluid intakes of elite level water polo players and swimmers. J Sci Med Sport, 5(3): 183-193, 2002.

30) Martarelli D, Ugoccioni F, Stauffacher F, Spataro A, Cocchioni M, and Pompei P. Assessment of body fluid balance and voluntary drinking in ultimate players during a match. J Sports Med Phys Fit, 49(3): 265-271, 2009.

31) Maughan RJ, Merson SJ, Broad NP, and Shirreffs SM. Fluid and electroyte intake and loss in elite soccer players during training. Int J Sport Nutr Exerc Metanol, 14(3): 333-346, 2004.

32) Shirreffs S M, Aragon-Vargas LF, Chamorro M, Maughan RJ, Serratosa L, and Zachwieja JJ. The sweating response of elite professional soccer players to training in the heat. Int J Sports Med, 26, 90-95, 2005.

33) Norton K, Whittinghan N, Carter L, Kerr D, Gore C, and Marfell-Jones M. Measurement techniques in anthropometry. In: Norton K, Olds T, (eds). Antropométrica. Sydney: UNSW, 1996.

34) Martins M, Aparecida J, Kleverson J, Works RH, Wagner R, Bohn JH, and Coppi A. A desidrataçao corporal de atletas amadores de futsal. Rev Bras 
Pres Fisio Exerc, 1(5): 24-36, 2007.

35) Barbero JC, Soto VM, Barbero V, and Granda-Vera $\mathrm{J}$. Match analysis and heart rate of futsal players during competition. J Sci Sports Med, 126 (1): 63-73, 2008.

36) Castagna C, D’Ottavio S, Granda-Vera J, and Barbero JC. Match demands of proffesional futsal: a case study. J Sci Med Sport, 12(4): 490-494, 2009.

37) Al-Jaser TA, and Hasan AAA. Fluid loss and body composition of elite Kuwaiti soccer players during a soccer match. J Sports Med Phys Fit, 46 (2): 281-285, 2006.

38) Ferguson MA, and McCoy S, Mosher PE. Exercise in a hot environment: comparison of two different fluid intake patterns. J Sports Med Phys Fit, 45(4): 501-506, 2005.

39) Hencken C, and White C. Anthropometric assessment of Premiership soccer players in relation to playing position. Eur J of Sport Sci, 6 (4): 205-211, 2006.

40) Hernández, J. Análisis de los parámetros espacio y tiempo en el fútbol sala. La distancia recorrida, el ritmo y dirección del desplazamiento del jugador durante un encuentro de competición. Apunts EF Deportes, 65: 32-44, 2001.

41) Hamouti N, Estévez E, Del Coso J, and Mora R. Fluid balance and sweat sodium concentration in elite indoor team sport players during training. Poster presented at 12th Annual Congress of the ECSS, 1114 July 2007, Jyvâskylâ, Finland.

42) Schröder H, Navarro E, Mora H, Seco J, Torregrosa JM, and Tramullas A. Dietary habits and fluid intake of a group of elite Spanish basketball players: a need for professional advice? Eur J Sport Sci 2004; 4(2): 1-15. 